\title{
Anthropometry, carbohydrate and lipid metabolism in the East Flanders Prospective Twin Survey: heritabilities
}

\author{
N. Y. Souren • A. D. C. Paulussen • R. J. F. Loos • \\ M. Gielen • G. Beunen • R. Fagard • C. Derom • \\ R. Vlietinck • M. P. Zeegers
}

Received: 2 May 2007 / Accepted: 19 June 2007 / Published online: 11 August 2007

(C) Springer-Verlag 2007

\begin{abstract}
Aims/hypothesis We determined the genetic contribution of 18 anthropometric and metabolic risk factors of type 2 diabetes using a young healthy twin population.

Methods Traits were measured in 240 monozygotic (MZ) and 138 dizygotic (DZ) twin pairs aged 18 to 34 years. Twins were recruited from the Belgian population-based East Flanders Prospective Twin Survey, which is characterised by its accurate zygosity determination and extensive collection of perinatal and placental data, including information on chorionicity. Heritability was estimated using structural equation modelling implemented in the $\mathrm{Mx}$ software package.
\end{abstract}

Electronic supplementary material The online version of this article (doi:10.1007/s00125-007-0784-z) contains supplementary material, which is available to authorised users.

\author{
N. Y. Souren $\cdot$ M. Gielen $\cdot$ M. P. Zeegers \\ Department of Genetics and Cell Biology, Maastricht University, \\ Maastricht, the Netherlands
}

N. Y. Souren • A. D. C. Paulussen $\cdot$ M. Gielen $\cdot$ M. P. Zeegers Nutrition and Toxicology Research Institute Maastricht (NUTRIM), Maastricht University,

Maastricht, the Netherlands

\section{A. D. C. Paulussen}

Division of Clinical Genetics, Academic Hospital Maastricht, Maastricht, the Netherlands

\section{R. J. F. Loos}

Medical Research Council Epidemiology Unit,

Cambridge, UK

\section{R. J. F. Loos · G. Beunen}

Department of Biomedical Kinesiology, Faculty of Kinesiology and Rehabilitation Sciences, Katholieke Universiteit Leuven,

Leuven, Belgium
Results Intra-pair correlations of the anthropometric and metabolic characteristics did not differ between MZ monochorionic and MZ dichorionic pairs; consequently heritabilities were estimated using the classical twin approach. For body mass, BMI and fat mass, quantitative sex differences were observed; genetic variance explained 84 , 85 and $81 \%$ of the total variation in men and 74,75 and $70 \%$ in women, respectively. Heritability estimates of the waist-to-hip ratio, sum of four skinfold thicknesses and lean body mass were 70,74 and $81 \%$, respectively. The heritability estimates of fasting glucose, fasting insulin, homeostasis model assessment of insulin resistance and beta cell function, as well as insulin-like growth factor binding protein-1 levels were $67,49,48,62$ and $47 \%$, in

\footnotetext{
R. Fagard

Hypertension and Cardiovascular Rehabilitation Unit,

Department of Cardiovascular Diseases,

Katholieke Universiteit Leuven,

Leuven, Belgium

C. Derom $\cdot$ R. Vlietinck

Department of Human Genetics,

Katholieke Universiteit Leuven,

Leuven, Belgium

M. P. Zeegers

Unit of Genetic Epidemiology, Department of Public Health and Epidemiology, University of Birmingham,

Birmingham, UK

A. D. C. Paulussen $(\varangle)$

Academic Hospital Maastricht, Division of Clinical Genetics, Joseph Bechlaan 113,

6229 GR Maastricht, the Netherlands

e-mail: aimee.paulussen@gen.unimaas.nl
} 
that order. Finally, for total cholesterol, LDL-cholesterol, HDL-cholesterol, total cholesterol:HDL-cholesterol ratio, triacylglycerol, NEFA and leptin levels, genetic factors explained $75,78,76,79,58,37$ and $53 \%$ of the total variation, respectively.

Conclusions/interpretation Genetic factors explain the greater part of the variation in traits related to obesity, glucose intolerance/insulin resistance and dyslipidaemia.

Keywords Anthropometry - Carbohydrate metabolism . Chorionicity - East Flanders Prospective Twin Survey . Heritability · Lipid metabolism · Metabolic risk factors . Structural equation modelling · Twin study · Type 2 diabetes

\begin{tabular}{|c|c|}
\hline \multicolumn{2}{|c|}{ Abbreviations } \\
\hline A & additive genetic effects \\
\hline $\mathrm{C}$ & common environmental effects \\
\hline $\mathrm{D}$ & non-additive genetic effects \\
\hline $\mathrm{DC}$ & dichorionic \\
\hline $\mathrm{DZ}$ & dizygotic \\
\hline DZF & dizygotic women \\
\hline DZM & dizygotic men \\
\hline DZOS & dizygotic opposite sex \\
\hline $\mathrm{E}$ & unique environmental effects \\
\hline EFPTS & East Flanders Prospective Twin Survey \\
\hline IGFBP-1 & insulin-like growth factor binding protein-1 \\
\hline MC & monochorionic \\
\hline $\mathrm{MZ}$ & monozygotic \\
\hline MZF & monozygotic women \\
\hline MZM & monozygotic men \\
\hline S4SF & sum of four skinfold thicknesses \\
\hline
\end{tabular}

\section{Introduction}

Type 2 diabetes is a heterogeneous disease that involves both genetic and environmental factors. Its incidence is rising rapidly worldwide and consequently much research is focused on the genetic components of the disorder, in order to get a better understanding of the pathogenesis and eventually to achieve better, more personalised diagnostics, treatment and prevention [1].

The starting point in the search for genes is to estimate the degree of heritability of intermediate traits leading to the disease in the studied population. Heritability is the proportion of phenotypic variation of a trait that can be attributed to genetic variation [2]. The degree of heritability is an important determinant of the power to detect and localise disease-related genes [3]. Although heritabilities can in principle be estimated from all kinds of related individuals, twin studies allow the variation to be split up into genetic, shared environmental and unique environmen- tal components, thus offering one of the most valid estimations [2].

A variety of studies estimating heritabilities of risk factors of type 2 diabetes in adult twins have been carried out. A summary of the larger studies ( $>200$ twin pairs) on the risk factors obesity, glucose intolerance/insulin resistance and dyslipidaemia is provided in Electronic Supplementary Material (ESM) Table 1. The heritability of BMI, the most frequently used measure of obesity, has been estimated extensively and ranges between 40 and 90\% [4-21]. For all the other traits, fewer studies have been performed; the total variation of fasting glucose and fasting insulin is explained by genetic factors for 12 to $50 \%[22,23]$ and 14 to $54 \%$ [7, 18, 22-24], respectively; for total cholesterol, LDL-cholesterol, HDL-cholesterol and triacylglycerol heritability estimates range between 0 and $98 \%$ [7, 10, 13, 17, 21, 25-34]. In addition to sample numbers and statistical methodologies used, the large variation in heritability estimates may also be caused by the genetic background of the studied populations and the environmental exposures experienced (see ESM Table 1). For the majority of intermediate traits related to type 2 diabetes, the number of larger studies performed is quite small and studies in which heritabilities of several risk factors of type 2 diabetes were estimated in the same population are even scarcer (ESM Table 1).

To determine the genetic contribution to type 2 diabetes, we used variance components modelling to estimate the heritabilities of 18 anthropometric and metabolic risk factors of the disease, including parameters quantifying obesity, glucose intolerance/insulin resistance and dyslipidaemia. In addition, we also determined the heritabilities of the hormones insulin-like growth factor binding protein1 (IGFBP-1), which has been shown to be related to several cardiovascular risk factors, and leptin, which plays a role as satiety signal regulating body composition and energy expenditure [35]. The characteristics were measured in 756 healthy twins, divided into 240 monozygotic (MZ) and 138 dizygotic (DZ) twin pairs in the age range of 18 to 34 years, recruited from the East Flanders Prospective Twin Survey (EFPTS).

\section{Methods}

Participants The EFPTS is a population-based twin register that started in 1964 and has recorded all multiple births in the Belgian Province of East Flanders until the present day. A detailed description of the EFPTS has been published [36]. Zygosity was determined using sequential analysis based on sex, fetal membranes, umbilical cord blood groups, placental alkaline phosphatase and DNA marker analysis. Between July 1964 and May 1982, the Twin 
Survey had registered 2,141 twin pairs who met the World Health Organization criteria for live born infants (birthweight $\geq 500$ g or gestational age $\geq 22$ weeks if birthweight unknown). Pairs of whom one or both members were stillborn, died in neonatal or later life or suffered from major congenital malformations were excluded. We randomly contacted 803 pairs using an envelope system. To assure equally distributed groups, we stratified for birth year and zygosity. Since the twin survey was originally set up to determine chorionicity, the number of $\mathrm{MZ}$ twin pairs was over sampled. Eventually, 424 twin pairs $(52.7 \%)$ volunteered to participate in the study. Sex, gestational age and birthweight did not differ between participants and non-participants (i.e. those who where eligible, but refused to participate or had not been contacted) $(p>0.05)$, although participants were slightly older than the non-participants and the proportion of monochorionic (MC) twins was higher in the group of participants $(p<0.05)$. A detailed description of the methods used to measure the anthropometric and metabolic characteristics of the twins is provided in the Electronic Supplementary Material. For the present analysis participants suffering from type 1 diabetes were excluded and only twin pairs of whom both members participated were incorporated. Consequently, phenotypic data were available for 378 complete pairs, consisting of 113 monozygotic men (MZM), 127 monozygotic women (MZF), 46 DZ men (DZM), 49 DZ women (DZF) and 43 DZ opposite sex (DZOS) pairs. Additionally, for the analysis of lipid and carbohydrate parameters, participants taking drugs with potential effects on lipid or carbohydrate metabolism were excluded $(n=11)$. Twins were randomly assigned to be the first or the second member of a pair. The Ethics Committee of the Faculty of Medicine of the Katholieke Universiteit Leuven approved the project and all participants gave informed consent.

Descriptive statistical analysis Anthropometric and metabolic characteristics are expressed as mean \pm SD according to chorion type, for men and women separately. BMI, sum of four skinfold thicknesses (S4SF), fat mass, IGFBP-1, fasting insulin, insulin resistance, beta cell function, leptin, total cholesterol:HDL-cholesterol ratio and triacylglycerol values had a skewed distribution. After transforming these data into natural logarithms a normal distribution was obtained and the transformed data were used when performing statistical tests. Differences in means between MZ MC, MZ dichorionic (DC) and DZ twins were calculated using the PROC MIXED method implemented in SAS version 9.1 (SAS Institute, Cary, NC, USA). A random intercept model was used, where the intercept of each twin pair was modelled as a function of the population intercept plus a unique contribution of the twin pair. In addition, we allowed the variance-covariance structure of the random intercept to differ between $\mathrm{MZ} \mathrm{MC}, \mathrm{MZ} \mathrm{DC}$ and DZ pairs. Differences in means were considered significant if the $2 d f F$ test indicated $p<0.05$.

For all traits, effects of potential covariates were also checked using the random intercept model of PROC MIXED, where the variance-covariance structure of the random intercept was allowed to differ between $\mathrm{MZ}$ and DZ pairs. The variables BMI, WHR and S4SF were checked for the effect of potential confounding by sex and age; body mass, fat mass and lean body mass were checked for the effect of sex, age and height; the blood parameters were checked for the effect of sex, age and fat (BMI, WHR or S4SF). Covariates were considered significant if $p<0.05$. Intra-pair correlation coefficients were calculated for MZ MC and MZ DC twin pairs and for each of the five sex by zygosity groups (MZM, MZF, DZM, DZF and DZOS) before and after adjustment for significant covariates using the Mx software package [37]. In addition, we used a linear regression analysis to test whether twin correlations differed between $\mathrm{MZ} \mathrm{MC}$ and $\mathrm{MZ} \mathrm{DC}$ twin pairs before and after adjusting for covariates.

Twin model fitting Twin methodology makes use of the fact that MZ twins are genetically identical, whereas DZ twins share $50 \%$ of their segregating genes. Assuming that $\mathrm{MZ}$ and DZ twins share their common environment to the same extent, a higher concordance rate in MZ twins than in DZ twins reflects genetic influences. To estimate the genetic and environmental components of variance of the traits, twin model fitting of raw data was implemented using the statistical package Mx [37]. Scripts were downloaded from the GenomEUtwin Mx-script library (http:/www.psy.vu.nl/ mxbib/). Univariate twin analyses were performed, where the phenotypic variance can be decomposed into additive genetic (A, additive effects of genes on multiple loci), nonadditive genetic $(\mathrm{D}$, interactions between alleles at the same locus [dominance] or on different loci [epistasis]), common environmental $(C$, environmental effects shared by twins reared in the same family) and unique environmental effects (E, environmental effects unique to the individual). $\mathrm{MZ}$ twins are assumed to share the same $A$ and $D$ genetic variance; DZ pairs are assumed to share one-half of the A variance and one-quarter of the $\mathrm{D}$ variance. The $\mathrm{C}$ variance is assumed to be the same for both $\mathrm{MZ}$ and $\mathrm{DZ}$ twin pairs. The broad sense heritability $\left(H^{2}\right)$, which estimates the extent to which variation of a trait in a population can be explained by genetic variation, is defined as the proportion of genetic variance to total phenotypic variance. As nonadditive genetic (D) and shared environmental effects (C) cannot be identified simultaneously in data from twins reared together, $\mathrm{ACE}$ and $\mathrm{ADE}$ models were fitted separately. The significance of variance components A, C 
or $\mathrm{D}$ in the model was tested by dropping these parameters and comparing the fit of the models [5].

To test whether genetic and environmental factors influence a trait to the same degree in men and women, we compared a quantitative heterogeneity model (variance components free to differ across sexes) with a homogeneity model (variance components equal for both sexes). In addition, we verified whether the distribution of a trait differed among men and women by testing a scalar model, which assumes that the female variance components are common multiples of the male variance components. In this model the variance components were constrained to be equal for both sexes, but total variances were allowed to differ between men and women (Fig. 1) [5].

If for a certain trait the correlation of the opposite-sex pairs is smaller than the correlations for the like-sexed DZ pairs, it is suggested that the correlation between additive genetic factors in opposite-sex pairs is smaller than 0.5. This indicates that different genetic factors influence this trait in men and women. To test this, a full heterogeneity model (variance components free to differ across sexes, plus the correlation between the additive genetic factors in opposite-sex pairs free to be estimated between 0 and 0.5 ) was compared with a quantitative heterogeneity model.

All variance components were estimated both unadjusted and adjusted for the covariates. In the models, phenotypic means were adjusted for significant covariates by modelling them as definition variables in the means model. The difference in fit between the nested models was evaluated with the likelihood ratio $\chi^{2}$ test, which uses the difference between the $-2 \log$ likelihood of the full and the restricted model. This difference is distributed as $\chi^{2}$. The $d f$ of the test were calculated as the difference in $d f$ between the models. When the $\chi^{2}$ was not statistically significant $(p<$ 0.05 ), the most parsimonious model was selected, i.e. the model with the best fit given the number of $d f$. When comparing the fit of non-nested models (e.g. ACE with ADE), the model with the lowest Akaike's information criterion was preferred.

\section{Results}

Descriptive statistical analysis The mean values of the anthropometric and metabolic characteristics of the twins are presented in Table 1 according to chorion type for men and women separately. In men, fasting glucose levels were lower in DZ twins than in MZ MC and MZ DC twins. In women, MZ DC twins were younger and had lower total cholesterol and LDL-cholesterol levels than MZ MC and DZ twins (Table 1).

The covariates adjusted for, the intra-pair correlations of MZ MC and MZ DC pairs, and the intra-pair correlations of
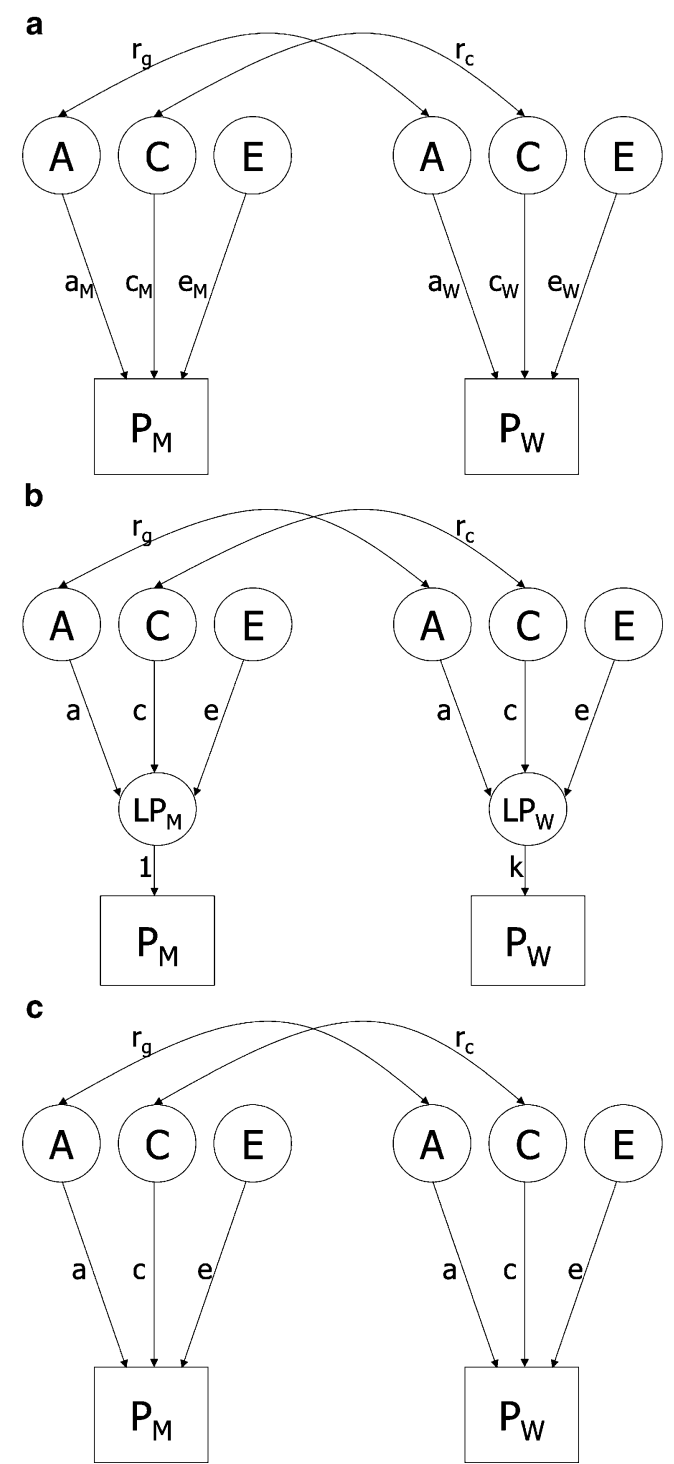

Fig. 1 Path diagram for a univariate quantitative heterogeneity (a), scalar (b) and homogeneity (c) model only presenting opposite sex pairs. Observed phenotypes $\left(\mathrm{P}_{\mathrm{M}}\right.$ and $\left.\mathrm{P}_{\mathrm{W}}\right)$ for the male and female twins are shown in rectangles, while latent factors (A, C and E) and latent phenotypes $\left(\mathrm{LP}_{\mathrm{M}}\right.$ and $\left.\mathrm{LP}_{\mathrm{W}}\right)$ are shown in circles. Path coefficients of observed variables on the different latent factors are shown in lower case: a, additive genetic effect; c, common environmental effect; e, unique environmental effect; $\mathrm{k}$, scalar factor. The genetic correlation is represented by $r_{g}$ ( 1 for $\mathrm{MZ}$ and 0.5 for DZ twins) and the common environmental correlation is represented by $r_{c}$ (1 for MZ and DZ twins)

each sex by zygosity group before and after adjustment are summarised in Table 2. Intra-pair correlations of the anthropometric and metabolic characteristics did not differ between MZ MC and MZ DC pairs ( $p>0.05)$. Adjusting for covariates strongly reduced the correlations of the leptin concentrations. The correlations of the other traits were only minimally affected by adjustment. Twin correlations for total cholesterol and LDL-cholesterol were high in both 
Table 1 Anthropometric and metabolic characteristics of the twin population according to chorion type for men and women separately in the EFPTS

\begin{tabular}{|c|c|c|c|c|c|c|c|c|}
\hline \multirow[t]{2}{*}{ Characteristic } & \multicolumn{4}{|l|}{ Men } & \multicolumn{4}{|l|}{ Women } \\
\hline & $\mathrm{MZ} \mathrm{MC}$ & $\mathrm{MZ} \mathrm{DC}$ & $\mathrm{DZ}$ & $p$ value & $\mathrm{MZ} \mathrm{MC}$ & $\mathrm{MZ} \mathrm{DC}$ & $\mathrm{DZ}$ & $p$ value \\
\hline$n$ & 134 & 92 & 135 & & 142 & 112 & 141 & \\
\hline Age (years) ${ }^{\mathrm{a}}$ & $25.3 \pm 4.5$ & $25.0 \pm 4.9$ & $25.7 \pm 4.7$ & 0.33 & $25.9 \pm 4.4$ & $24.0 \pm 4.8$ & $25.7 \pm 4.6$ & 0.02 \\
\hline Body height $(\mathrm{cm})$ & $178.0 \pm 5.7$ & $178.3 \pm 7.2$ & $178.4 \pm 6.5$ & 0.92 & $165.0 \pm 6.3$ & $165.6 \pm 6.1$ & $166.2 \pm 6.4$ & 0.59 \\
\hline Body mass (kg) & $70.7 \pm 10.5$ & $69.6 \pm 8.4$ & $70.9 \pm 10.2$ & 0.67 & $60.5 \pm 9.7$ & $60.5 \pm 10.6$ & $60.8 \pm 10.2$ & 0.98 \\
\hline BMI $\left(\mathrm{kg} / \mathrm{m}^{2}\right)$ & $22.1 \pm 1.1$ & $21.8 \pm 1.1$ & $22.1 \pm 1.2$ & 0.73 & $22.0 \pm 1.2$ & $21.8 \pm 1.2$ & $21.8 \pm 1.2$ & 0.86 \\
\hline WHR (\%) & $83.4 \pm 5.4$ & $83.4 \pm 5.8$ & $82.8 \pm 5.5$ & 0.84 & $73.4 \pm 4.5$ & $73.3 \pm 4.6$ & $72.5 \pm 4.3$ & 0.30 \\
\hline $\mathrm{S} 4 \mathrm{SF}(\mathrm{mm})^{\mathrm{b}}$ & $35.9 \pm 1.5$ & $34.6 \pm 1.5$ & $34.8 \pm 1.5$ & 0.89 & $57.1 \pm 1.4$ & $55.6 \pm 1.5$ & $53.6 \pm 1.4$ & 0.50 \\
\hline Fat mass $(\mathrm{kg})^{\mathrm{b}}$ & $11.9 \pm 1.6$ & $11.2 \pm 1.5$ & $12.2 \pm 1.5$ & 0.33 & $16.9 \pm 1.3$ & $16.7 \pm 1.4$ & $16.8 \pm 1.3$ & 0.95 \\
\hline Lean body mass $(\mathrm{kg})$ & $57.7 \pm 6.9$ & $57.6 \pm 6.0$ & $57.7 \pm 6.6$ & 0.99 & $42.9 \pm 5.1$ & $43.1 \pm 5.6$ & $43.4 \pm 6.0$ & 0.89 \\
\hline IGFBP-1 (ng/ml $)^{\mathrm{b}}$ & $11.0 \pm 1.9$ & $10.3 \pm 1.8$ & $11.5 \pm 1.9$ & 0.46 & $16.8 \pm 2.0$ & $16.6 \pm 2.2$ & $18.4 \pm 2.3$ & 0.58 \\
\hline Fasting insulin $(\mathrm{pmol} / \mathrm{l})^{\mathrm{b}}$ & $33.5 \pm 1.5$ & $32.7 \pm 1.6$ & $32.7 \pm 1.6$ & 0.94 & $38.6 \pm 1.5$ & $35.8 \pm 1.6$ & $40.1 \pm 1.5$ & 0.24 \\
\hline Insulin resistance (HOMA) $)^{b}$ & $1.2 \pm 1.6$ & $1.2 \pm 1.6$ & $1.2 \pm 1.6$ & 0.69 & $1.3 \pm 1.5$ & $1.2 \pm 1.7$ & $1.4 \pm 1.5$ & 0.26 \\
\hline Fasting glucose (mmol/l) & $5.0 \pm 0.5$ & $4.9 \pm 0.4$ & $4.8 \pm 0.4$ & 0.01 & $4.5 \pm 0.3$ & $4.6 \pm 0.4$ & $4.6 \pm 0.4$ & 0.23 \\
\hline Beta cell function (HOMA) ${ }^{b}$ & $77.2 \pm 1.5$ & $78.2 \pm 1.6$ & $86.5 \pm 1.7$ & 0.10 & $135.2 \pm 1.7$ & $115.7 \pm 1.6$ & $126.7 \pm 1.6$ & 0.17 \\
\hline Leptin $(\mathrm{ng} / \mathrm{ml})^{\mathrm{b}}$ & $1.7 \pm 3.0$ & $1.4 \pm 2.9$ & $1.7 \pm 3.0$ & 0.42 & $11.5 \pm 2.1$ & $11.2 \pm 2.2$ & $11.5 \pm 1.9$ & 0.92 \\
\hline Total cholesterol $(\mathrm{mmol} / \mathrm{l})$ & $4.8 \pm 0.9$ & $4.7 \pm 1.0$ & $4.9 \pm 1.1$ & 0.31 & $5.3 \pm 0.9$ & $4.9 \pm 0.8$ & $5.3 \pm 1.0$ & 0.006 \\
\hline LDL-cholesterol (mmol/l) & $3.0 \pm 0.9$ & $2.9 \pm 0.9$ & $3.1 \pm 1.0$ & 0.35 & $3.1 \pm 0.8$ & $2.7 \pm 0.8$ & $2.9 \pm 0.8$ & 0.012 \\
\hline HDL-cholesterol (mmol/l) & $1.3 \pm 0.3$ & $1.3 \pm 0.3$ & $1.4 \pm 0.4$ & 0.94 & $1.8 \pm 0.4$ & $1.8 \pm 0.4$ & $1.9 \pm 0.4$ & 0.39 \\
\hline Total cholesterol:HDL-cholesterol ratio ${ }^{\mathrm{b}}$ & $3.6 \pm 1.4$ & $3.5 \pm 1.3$ & $3.7 \pm 1.4$ & 0.67 & $3.0 \pm 1.3$ & $2.8 \pm 1.3$ & $2.9 \pm 1.3$ & 0.34 \\
\hline Triacylglycerol $(\mathrm{mmol} / \mathrm{l})^{\mathrm{b}}$ & $0.9 \pm 1.6$ & $0.9 \pm 1.5$ & $0.9 \pm 1.5$ & 0.78 & $0.9 \pm 1.5$ & $0.9 \pm 1.5$ & $0.9 \pm 1.5$ & 0.83 \\
\hline NEFA (mmol/l) & $0.5 \pm 0.2$ & $0.5 \pm 0.2$ & $0.5 \pm 0.2$ & 0.05 & $0.7 \pm 0.2$ & $0.7 \pm 0.3$ & $0.7 \pm 0.2$ & 0.81 \\
\hline
\end{tabular}

Data are expressed as mean \pm SD

HOMA, homeostasis model assessment

${ }^{a} p$ value calculated using standard linear regression, because convergence criteria could not be met using a random intercept model

${ }^{\mathrm{b}}$ Geometric mean $\pm \mathrm{SD}$

$\mathrm{MZ}$ and DZ twin pairs, indicating a common environmental effect. The DZ correlations of IGFBP-1, fasting insulin and insulin resistance were less then one-half of the MZ correlations, suggesting that non-additive genetic effects might be important. Correlations of the other traits were in agreement with a model containing additive genetic and unique environmental influences (Table 2).

Twin model fitting The variance components and 95\% CIs of the best fitting models before and after adjustment for covariates are presented in Table 3. The best fitting model for lean body mass and the obesity parameters body mass, BMI, WHR, S4SF and fat mass was an AE model containing a major genetic component. For total cholesterol and LDL-cholesterol, the ACE model was the best fitting model. However, after adjusting for covariates, the AE model became the best fitting model. For IGFBP-1, fasting insulin and insulin resistance, a DE model containing a non-additive genetic and unique environmental component had the best fit. The variation of the remaining blood parameters, including fasting glucose, beta cell function, leptin, HDL-cholesterol, total cholesterol:HDL-cholesterol ratio, triacylglycerol and NEFA levels were best explained by an AE model (Table 3).

Quantitative sex differences were present in body mass, BMI, WHR, S4SF, fat mass, lean body mass, leptin and total cholesterol:HDL-cholesterol ratio, because variance components estimates were significantly different between men and women (Table 3). The influences of additive genetic factors were larger in men than in women. For some traits, scalar sex differences were observed, implying that although variance components are equal across sexes, the total variances differ. As a result, total variance of IGFBP1, HDL-cholesterol and NEFA levels in women was larger than in men, but smaller for fasting glucose and HDLcholesterol levels (Table 3).

After adjusting for covariates, quantitative sex differences remained significant only for body mass, BMI and fat mass (Table 3). In addition, scalar sex differences were significant for WHR, S4SF, lean body mass, IGFBP-1, fasting glucose, leptin, HDL-cholesterol, total cholesterol:HDLcholesterol ratio and NEFA levels. Total variance of IGFBP-1, HDL-cholesterol and NEFA levels was larger in 
Table 2 Intra-pair correlations of MZ MC and MZ DC pairs, and of each sex by zygosity group before and after adjusting for covariates in the EFPTS

\begin{tabular}{|c|c|c|c|c|c|c|c|c|}
\hline \multirow[t]{2}{*}{ Characteristic } & \multicolumn{2}{|c|}{ Monozygotic } & \multicolumn{2}{|c|}{ Monozygotic } & \multicolumn{3}{|l|}{ Dizygotic } & \multirow[t]{2}{*}{ Covariates } \\
\hline & $\mathrm{MC}$ & $\mathrm{DC}$ & Men & Women & Men & Women & OS & \\
\hline$n$ (of pairs) & 138 & 102 & 113 & 127 & 46 & 49 & 43 & \\
\hline Body mass & $0.85 / 0.79$ & $0.84 / 0.76$ & $0.86 / 0.82$ & $0.76 / 0.73$ & $0.38 / 0.28$ & $0.58 / 0.57$ & $0.26 / 0.35$ & Sex, age, height \\
\hline BMI & $0.80 / 0.78$ & $0.81 / 0.77$ & $0.86 / 0.83$ & $0.77 / 0.74$ & $0.46 / 0.31$ & $0.53 / 0.56$ & $0.47 / 0.46$ & Age \\
\hline WHR & $0.87 / 0.69$ & $0.88 / 0.71$ & $0.79 / 0.74$ & $0.70 / 0.66$ & $0.39 / 0.28$ & $0.44 / 0.48$ & $0.31 / 0.15$ & Sex, age \\
\hline S4SF & $0.82 / 0.73$ & $0.84 / 0.75$ & $0.81 / 0.79$ & $0.72 / 0.68$ & $0.46 / 0.37$ & $0.64 / 0.63$ & $0.36 / 0.31$ & Sex, age \\
\hline Fat mass & $0.85 / 0.78$ & $0.85 / 0.75$ & $0.85 / 0.82$ & $0.73 / 0.69$ & $0.46 / 0.36$ & $0.43 / 0.46$ & $0.42 / 0.35$ & Sex, age \\
\hline Lean body mass & $0.93 / 0.81$ & $0.93 / 0.79$ & $0.86 / 0.82$ & $0.79 / 0.78$ & $0.43 / 0.39$ & $0.65 / 0.58$ & $0.25 / 0.39$ & Sex, age, height \\
\hline IGFBP-1 & $0.49 / 0.39$ & $0.60 / 0.53$ & $0.55 / 0.51$ & $0.45 / 0.43$ & $0.31 / 0.21$ & $0.08 / 0.06$ & $0.12 /-0.05$ & Sex, age, BMI \\
\hline Fasting insulin & $0.57 / 0.48$ & $0.52 / 0.50$ & $0.49 / 0.45$ & $0.58 / 0.52$ & $0.07 / 0.13$ & $0.18 / 0.19$ & $0.07 /-0.01$ & Age, S4SF \\
\hline Insulin resistance & $0.54 / 0.47$ & $0.53 / 0.50$ & $0.49 / 0.46$ & $0.57 / 0.51$ & $0.03 / 0.08$ & $0.14 / 0.17$ & $0.04 /-0.05$ & Sex, age, S4SF \\
\hline Fasting glucose & $0.74 / 0.66$ & $0.73 / 0.67$ & $0.65 / 0.65$ & $0.70 / 0.69$ & $0.28 / 0.24$ & $0.57 / 0.60$ & $0.31 / 0.32$ & Sex, BMI \\
\hline Beta cell function & $0.71 / 0.58$ & $0.66 / 0.60$ & $0.52 / 0.50$ & $0.68 / 0.66$ & $0.32 / 0.40$ & $0.47 / 0.46$ & $0.37 / 0.33$ & Sex, age, S4SF \\
\hline Leptin & $0.85 / 0.53$ & $0.85 / 0.57$ & $0.70 / 0.58$ & $0.64 / 0.52$ & $0.35 / 0.02$ & $0.66 / 0.31$ & $0.38 / 0.37$ & Sex, age, S4SF \\
\hline Total cholesterol & $0.76 / 0.74$ & $0.77 / 0.72$ & $0.78 / 0.74$ & $0.73 / 0.73$ & $0.52 / 0.51$ & $0.51 / 0.44$ & $0.63 / 0.51$ & Age, S4SF \\
\hline LDL-cholesterol & $0.78 / 0.79$ & $0.81 / 0.74$ & $0.81 / 0.79$ & $0.77 / 0.75$ & $0.52 / 0.51$ & $0.59 / 0.52$ & $0.68 / 0.58$ & Sex, age, S4SF \\
\hline HDL-cholesterol & $0.78 / 0.71$ & $0.84 / 0.77$ & $0.75 / 0.76$ & $0.74 / 0.74$ & $0.31 / 0.30$ & $0.44 / 0.44$ & $0.52 / 0.52$ & Sex, S4SF \\
\hline Total cholesterol:HDL-cholesterol ratio & $0.81 / 0.78$ & $0.86 / 0.81$ & $0.84 / 0.82$ & $0.78 / 0.76$ & $0.50 / 0.41$ & $0.50 / 0.49$ & $0.65 / 0.54$ & Age, WHR \\
\hline Triacylglycerol & $0.58 / 0.56$ & $0.67 / 0.60$ & $0.59 / 0.54$ & $0.63 / 0.60$ & $0.29 / 0.41$ & $0.34 / 0.34$ & $0.16 / 0.17$ & Sex, S4SF \\
\hline NEFA & $0.49 / 0.35$ & $0.43 / 0.39$ & $0.39 / 0.38$ & $0.34 / 0.37$ & $0.10 / 0.14$ & $0.20 / 0.18$ & $0.25 / 0.26$ & Sex, S4SF \\
\hline
\end{tabular}

Values are unadjusted intra-pair correlation/adjusted intra-pair correlation.

OS, opposite sex

women than in men, but smaller for WHR, S4SF, lean body mass, fasting glucose, leptin and total cholesterol:HDLcholesterol ratio (Table 3).

The adjusted correlations of WHR, fasting insulin and triacylglycerol levels for opposite-sex pairs were smaller than the correlations for like-sexed DZ pairs, suggesting that different genetic factors influence this trait in men and women (Table 2). However, the correlations between the additive genetic factors in opposite-sex pairs were not significantly smaller than $0.5(p>0.05)$.

Broad-sense heritability estimates (encompassing both additive and non-additive genetic effects) were slightly lower after adjusting for covariates, with the exception of total cholesterol and LDL-cholesterol, which had a higher heritability after adjustment (Table 3).

In summary, heritability estimates of body mass, BMI and fat mass were 84,85 and $81 \%$ for men and 74,75 and $70 \%$ for women, respectively. WHR, S4SF and lean body mass had heritability estimates of 70,74 and $81 \%$, correspondingly. For fasting glucose, fasting insulin, insulin resistance, beta cell function and IGFBP-1 levels, genetic factors explained $67,49,48,62$ and $47 \%$ of the total variation, respectively. Finally, heritability estimates of total cholesterol, triacylglycerol, HDL-cholesterol, LDL-cholesterol, total cholesterol:HDL-cholesterol ratio, NEFA and leptin levels were $75,58,76,78,79,37$ and 53\%, respectively (Table 3).

\section{Discussion}

To determine the genetic contribution to type 2 diabetes, we estimated the heritabilities of 18 anthropometric and metabolic characteristics related to this disease, including parameters quantifying obesity, glucose intolerance/insulin resistance and dyslipidaemia. The traits were measured in $138 \mathrm{DZ}$ and $240 \mathrm{MZ}$ young healthy twin pairs recruited from the population-based EFPTS [36].

Obesity, defined as excess accumulation of adipose tissue, is a complicated trait to measure and numerous methods exist for its determination [38]. In the present study several parameters defining obesity, including body mass, BMI, S4SF, WHR and fat mass were used and heritability estimates ranged from 70 to $85 \%$. According to ESM Table 1, the heritabilities identified by us for BMI and body mass are in agreement with those reported in other twin studies, but the heritability identified by us for WHR is somewhat higher [7, 15, 18, 39]. Heritability estimates for S4SF and fat mass are not often reported and therefore we were not able to make a valid comparison. Despite the variety of measurements used to quantify obesity, the heritabilities of the different measurements were consistently in a high range, indicating that the contribution of genetic factors to total phenotypic variation in obesity is of great importance in the studied twin sample. 
Diabetologia (2007) 50:2107-2116

2113

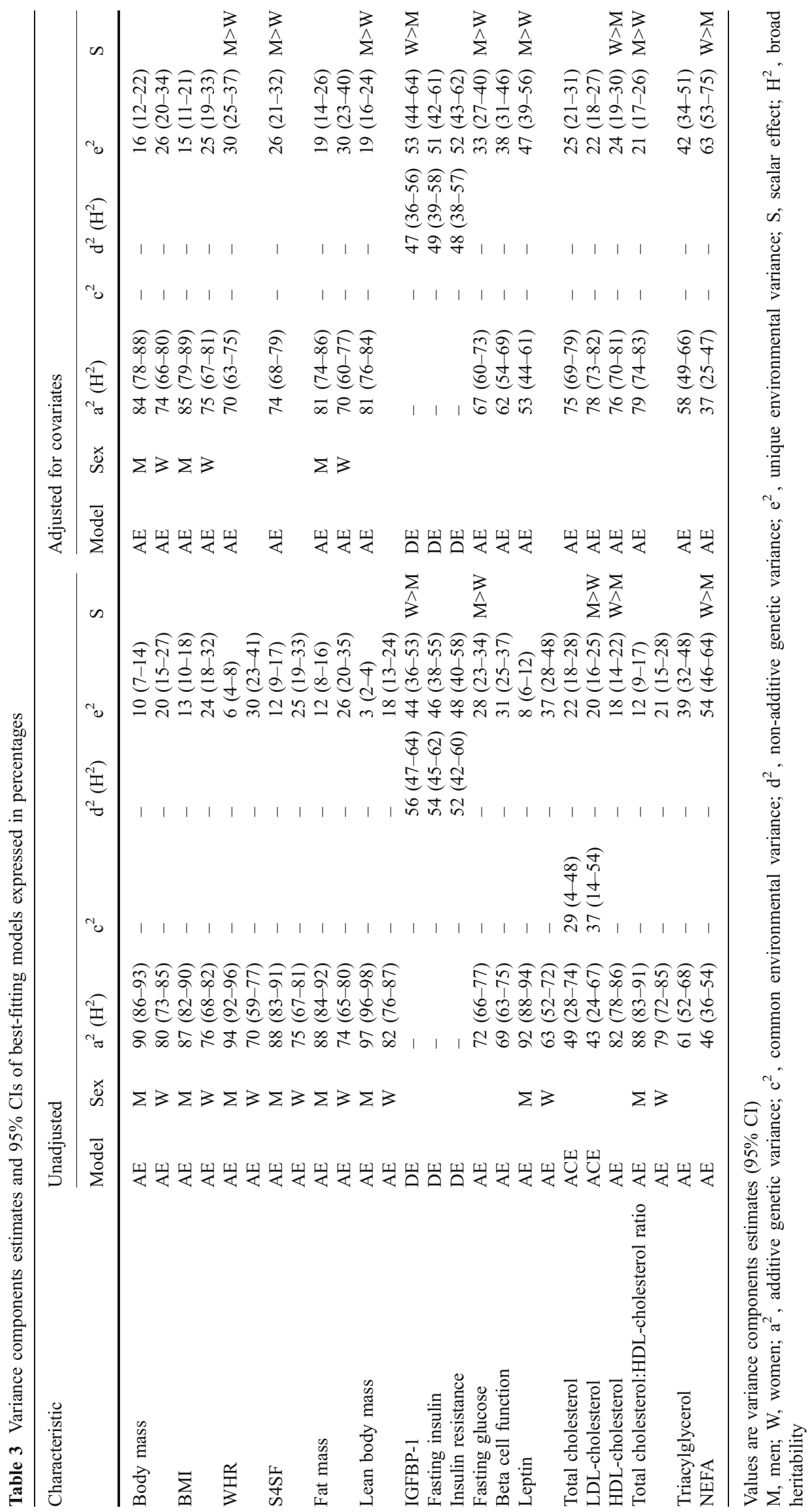

望 Springer 
Quantitative sex differences were significant for body mass, BMI and fat mass, with heritability estimates of 84,85 and $81 \%$ in men and 74,75 and $70 \%$ in women, respectively. Our results confirm those from other twin studies reporting quantitative sex differences in the heritability of body mass and BMI [4-6, 9, 20, 40]. However, in other twin studies the highest heritability estimates were not always observed in men (ESM Table 1), indicating that the influence of environmental factors in the total variation of these traits according to sex may vary in different populations.

In the present study, $49 \%$ of the total variation of fasting insulin was explained by genetic factors, which is in agreement with other twin studies (ESM Table 1) [41, 42]. The heritability of fasting glucose $\left(H^{2}=67 \%\right)$ was higher than those observed in other twin studies, where it ranged between 12 and 58\% (ESM Table 1) [42, 43]. The heritabilities of beta cell function $\left(H^{2}=62 \%\right)$ and insulin resistance $\left(H^{2}=48 \%\right)$ was not higher than those of fasting glucose $\left(H^{2}=67 \%\right)$ and fasting insulin levels $\left(H^{2}=49 \%\right)$. This indicates that no additional power was obtained by calculating these alternative phenotypic markers with the homeostasis model assessment.

The variation of total cholesterol, triacylglycerol, HDLcholesterol, LDL-cholesterol and total cholesterol:HDLcholesterol ratio was primarily explained by additive genetic factors, accounting for $75,58,76,78$ and $79 \%$ of the total variance, respectively. No evidence was observed for quantitative sex differences in heritability estimates for these traits. The percentages are slightly higher than the heritability estimates reported in the literature, but are in the same high range (ESM Table 1). To the best of our knowledge, ours is the first large twin study reporting the heritability of NEFA levels, which was $37 \%$. This is somewhat surprising, since excessive circulating fatty acids represent a major contributor to the development of insulin resistance [44]. The heritability determined for NEFA levels in the current study was low compared with those reported for the other blood lipid parameters, indicating that environmental factors, e.g. nutrition, may be more important in determining the variation of NEFA levels than genetic factors.

Additive genetic variance explained $53 \%$ of the variation of total leptin concentration. In other western adult twin studies, heritabilities of total leptin concentrations ranged from 34 to $55 \%$ [45, 46], which is in agreement with our findings. Compared with other traits, the correlations and heritability estimates of leptin were strongly reduced after adjusting for covariates, which is probably caused by the adjustment for fat (using S4SF). This is not very surprising, since leptin is synthesised in and secreted from adipose tissue and plasma leptin levels are increased in obese humans in direct proportion to body fat mass [35]. The heritability of IGFBP-1 $\left(H^{2}=47 \%\right)$ levels determined in our study was also relatively high, since the heritability in two other twin studies ranged from 0 to $36 \%$ [41, 47]. Interestingly, the heritabilities of IGFBP-1 levels in the latter studies were determined in older twins (mean age 63 years). This might suggest that the heritability of IGFBP-1 decreases with advancing age. Longitudinal twin studies need to be carried out to verify this observation.

We are the first to report that a model containing nonadditive instead of additive genetic factors is the best-fitting model for insulin resistance, fasting insulin and IGFBP-1 levels [7, 18, 22, 24, 41-43]. In addition to the twin model fitting procedure, twin correlations can also give an impression of whether non-additive genetic effects might be involved, i.e. a DZ correlation of less than one-half of the MZ correlation suggests a contribution of non-additive genetic effects [18, 41-43]. The smaller sample size of some studies could be responsible for their not observing a DE model. Furthermore, the presence of non-additive genetic effects has not always been tested. However, if non-additive genetic effects are observed, this implies that a part of the variance is explained by interactions between alleles at the same locus or on different loci. Although this observation is likely to be the result of lack of power, we cannot exclude real non-additive genetic effects in the absence of additive genetic effects, as these three traits are closely related to or are a direct gene product.

MZ MC twins have a more adverse intra-uterine environment than $\mathrm{MZ} \mathrm{DC}$ and $\mathrm{DZ}$ twins, resulting in a significantly lower weight at birth and higher perinatal mortality and morbidity [36]. Hence, it has been hypothesised that for disorders like type 2 diabetes, in the development of which prenatal environment plays a role, the classical twin study might be an unreliable method of estimating heritabilities $[48,49]$. In the current twin sample, intra-pair correlations did not differ between $\mathrm{MZ} \mathrm{MC}$ and MZ DC twins, suggesting that the chorion type of MZ twins did not bias the heritability estimates of the studied traits.

With the exception of NEFA levels, the genetic contribution to the traits studied in our twin sample was high. When comparing the heritability values found by us with those reported in other twin studies (Electronic Supplementary Material Table 1), our heritability estimates are in a slightly higher range. An important aspect affecting heritability estimates is the accuracy of the zygosity determination used in the present study via sequential analysis based on sex, fetal membranes, umbilical cord blood groups, placental alkaline phosphatase and DNA marker analysis. In other twin studies, zygosity was often determined using questionnaires [4], which sometimes leads to misclassification and consequently to underestimation of heritability [50]. Our high heritability estimates might also be a consequence of the homogeneous composition of the studied sample. All twins included were born 
in the Belgian province of East Flanders, which is a relatively small but rather densely populated area [36]. Another factor possibly contributing to the high heritability estimates is age, as shown by the fact that several large twin studies have reported a decrease in the heritability of obesity (BMI) in adults with increasing age $[5,12,16]$. Our twin sample is young (mean $=25$ years) and the age range is small (18-34 years). As the power to detect quantitative trait loci is positively correlated with the size of the genetic effect [3], our study suggests that the search for candidate genes might be more efficient in a young homogeneous population.

In conclusion, this study is the first large study to give a comprehensive overview of the heritabilities of multiple risk factors related to type 2 diabetes within the same twin sample. The variation of traits related to obesity, glucose intolerance/insulin resistance and dyslipidaemia in this Belgian twin sample is in general highly explained by genetic factors. These high heritabilities are very promising for follow-up to this research, in which, in order to explain some of the genetic variance observed, sib-pair linkage analyses will be performed using microsatellite markers located in the close vicinity of selected candidate genes.

Acknowledgements This work was financially supported by the Dutch Diabetes Research Foundation (DFN 2002.00.15) and the National Fund for Scientific Research Belgium (G.0383.03 and G.3.0269.97). The EFPTS has been partly supported by grants from Funds of Scientific Research Flanders and by the Association for Scientific Research in Multiple Births (VZW Twins). We are grateful to all twins participating in this study. We thank I. Berckmoes, A. Roossens, L. De Zeure and M. Van Heuverswyn for fieldwork and technical assistance. We thank M. Thomis for reviewing our manuscript.

Duality of interest The authors declare that there is no duality of interest associated with this manuscript.

\section{References}

1. van Tilburg J, van Haeften TW, Pearson P, Wijmenga C (2001) Defining the genetic contribution of type 2 diabetes mellitus. J Med Genet 38:569-578

2. Boomsma D, Busjahn A, Peltonen L (2002) Classical twin studies and beyond. Nat Rev Genet 3:872-882

3. Snieder H, Harshfield GA, Treiber FA (2003) Heritability of blood pressure and hemodynamics in African- and European-American youth. Hypertension 41:1196-1201

4. Schousboe K, Willemsen G, Kyvik KO et al (2003) Sex differences in heritability of BMI: a comparative study of results from twin studies in eight countries. Twin Res 6:409-421

5. Neale MC, Cardon LR (1992) Methodology for Genetic Studies of Twins and Families. Kluwer, Dordrecht

6. Herskind AM, McGue M, Sorensen TI, Harvald B (1996) Sex and age specific assessment of genetic and environmental influences on body mass index in twins. Int J Obes Relat Metab Disord 20:106-113

7. Poulsen P, Vaag A, Kyvik K, Beck-Nielsen H (2001) Genetic versus environmental aetiology of the metabolic syndrome among male and female twins. Diabetologia 44:537-543
8. Schousboe K, Visscher PM, Erbas B et al (2004) Twin study of genetic and environmental influences on adult body size, shape, and composition. Int J Obes Relat Metab Disord 28:39-48

9. Korkeila M, Kaprio J, Rissanen A, Koskenvuo M (1991) Effects of gender and age on the heritability of body mass index. Int $\mathrm{J}$ Obes 15:647-654

10. Austin MA, King MC, Bawol RD, Hulley SB, Friedman GD (1987) Risk factors for coronary heart disease in adult female twins. Genetic heritability and shared environmental influences. Am J Epidemiol 125:308-318

11. Austin MA, Friedlander Y, Newman B, Edwards K, Mayer-Davis EJ, King MC (1997) Genetic influences on changes in body mass index: a longitudinal analysis of women twins. Obes Res 5:326-331

12. Carmichael CM, McGue M (1995) A cross-sectional examination of height, weight, and body mass index in adult twins. J Gerontol A Biol Sci Med Sci 50:B237-244

13. Feinleib M, Garrison RJ, Fabsitz R et al (1977) The NHLBI twin study of cardiovascular disease risk factors: methodology and summary of results. Am J Epidemiol 106:284-285

14. Stunkard AJ, Foch TT, Hrubec Z (1986) A twin study of human obesity. JAMA 256:51-54

15. Selby JV, Newman B, Quesenberry CP Jr. et al (1990) Genetic and behavioral influences on body fat distribution. Int $\mathrm{J}$ Obes 14:593-602

16. Fabsitz RR, Carmelli D, Hewitt JK (1992) Evidence for independent genetic influences on obesity in middle age. Int $\mathrm{J}$ Obes Relat Metab Disord 16:657-666

17. Hong Y, Pedersen NL, Brismar K, de Faire U (1997) Genetic and environmental architecture of the features of the insulin-resistance syndrome. Am J Hum Genet 60:143-152

18. Nelson TL, Vogler GP, Pedersen NL, Hong Y, Miles TP (2000) Genetic and environmental influences on body fat distribution, fasting insulin levels and CVD: are the influences shared? Twin Res 3:43-50

19. Stunkard AJ, Harris JR, Pedersen NL, McClearn GE (1990) The body-mass index of twins who have been reared apart. $\mathrm{N}$ Engl $\mathrm{J}$ Med 322:1483-1487

20. Harris JR, Tambs K, Magnus P (1995) Sex-specific effects for body mass index in the new Norwegian twin panel. Genet Epidemiol 12:251-265

21. Knoblauch H, Busjahn A, Muller-Myhsok B et al (1999) Peroxisome proliferator-activated receptor gamma gene locus is related to body mass index and lipid values in healthy nonobese subjects. Arterioscler Thromb Vasc Biol 19:2940-2944

22. Schousboe K, Visscher PM, Henriksen JE, Hopper JL, Sorensen TI, Kyvik KO (2003) Twin study of genetic and environmental influences on glucose tolerance and indices of insulin sensitivity and secretion. Diabetologia 46:1276-1283

23. Snieder H, Boomsma DI, van Doornen LJ, Neale MC (1999) Bivariate genetic analysis of fasting insulin and glucose levels. Genet Epidemiol 16:426-446

24. Mayer EJ, Newman B, Austin MA et al (1996) Genetic and environmental influences on insulin levels and the insulin resistance syndrome: an analysis of women twins. Am J Epidemiol 143:323-332

25. Beekman M, Heijmans BT, Martin NG et al (2002) Heritabilities of apolipoprotein and lipid levels in three countries. Twin Res 5:87-97

26. Whitfield JB, Martin NG (1983) Plasma lipids in twins. Environmental and genetic influences. Atherosclerosis 48:265-277

27. Snieder H, van Doornen LJ, Boomsma DI (1997) The age dependency of gene expression for plasma lipids, lipoproteins, and apolipoproteins. Am J Hum Genet 60:638-650

28. Friedlander Y, Austin MA, Newman B, Edwards K, Mayer-Davis EI, King MC (1997) Heritability of longitudinal changes in coronary-heart-disease risk factors in women twins. Am J Hum Genet 60:1502-1512 
29. Middelberg RP, Spector TD, Swaminathan R, Snieder H (2002) Genetic and environmental influences on lipids, lipoproteins, and apolipoproteins: effects of menopause. Arterioscler Thromb Vasc Biol 22:1142-1147

30. Heller DA, de Faire U, Pedersen NL, Dahlen G, McClearn GE (1993) Genetic and environmental influences on serum lipid levels in twins. N Engl J Med 328:1150-1156

31. Iliadou A, Lichtenstein P, de Faire U, Pedersen NL (2001) Variation in genetic and environmental influences in serum lipid and apolipoprotein levels across the lifespan in Swedish male and female twins. Am J Med Genet 102:48-58

32. McCaffery JM, Poque-Geile MF, Muldoon MF, Debski TT, Wing RR, Manuck SB (2001) The nature of the association between diet and serum lipids in the community: a twin study. Health Psychol 20:341-350

33. Middelberg R, Heath AC, Martin NG, Whitfield JB (2005) Evidence of age-dependent genetic influences on plasma total cholesterol. Eur J Cardiovasc Prev Rehabil 12:380-386

34. Fenger M, Schousboe K, Sorensen TI, Kyvik KO (2007) Variance decomposition of apolipoproteins and lipids in Danish twins. Atherosclerosis 191:40-47

35. Rosenbaum M, Leibel RL, Hirsch J (1997) Obesity. N Engl J Med 337:396-407

36. Loos R, Derom C, Vlietinck R, Derom R (1998) The East Flanders Prospective Twin Survey (Belgium): a population-based register. Twin Res 1:167-175

37. Neale MC, Boker SM, Xie G, Maes HH (2002) Mx: Statistical Modeling, 6th ed. VCU Department of Psychiatry, Richmond, VA

38. Moyad MA (2004) Fad diets and obesity—Part I: Measuring weight in a clinical setting. Urol Nurs 24:114-119

39. Rose KM, Newman B, Mayer-Davis EJ, Selby JV (1998) Genetic and behavioral determinants of waist-hip ratio and waist circumference in women twins. Obes Res 6:383-392

40. Allison DB, Heshka S, Neale MC, Lykken DT, Heymsfield SB (1994) A genetic analysis of relative weight among 4,020 twin pairs, with an emphasis on sex effects. Health Psychol 13:362365

41. Hong Y, Pedersen NL, Brismar K, Hall K, de Faire U (1996) Quantitative genetic analyses of insulin-like growth factor 1 (IGF-1), IGF-binding protein-1, and insulin levels in middle-aged and elderly twins. J Clin Endocrinol Metab 81:1791-1797

42. Lehtovirta M, Kaprio J, Forsblom C, Eriksson J, Tuomilehto J, Groop L (2000) Insulin sensitivity and insulin secretion in monozygotic and dizygotic twins. Diabetologia 43:285-293

43. Baird J, Osmond C, MacGregor A, Snieder H, Hales CN, Phillips DI (2001) Testing the fetal origins hypothesis in twins: the Birmingham twin study. Diabetologia 44:33-39

44. Stumvoll M, Goldstein BJ, van Haeften TW (2005) Type 2 diabetes: principles of pathogenesis and therapy. Lancet 365:1333-1346

45. Narkiewicz K, Szczech R, Winnicki M et al (1999) Heritability of plasma leptin levels: a twin study. J Hypertens 17:27-31

46. Kaprio J, Eriksson J, Lehtovirta M, Koskenvuo M, Tuomilehto J (2001) Heritability of leptin levels and the shared genetic effects on body mass index and leptin in adult Finnish twins. Int J Obes Relat Metab Disord 25:132-137

47. Harrela M, Koistinen H, Kaprio J et al (1996) Genetic and environmental components of interindividual variation in circulating levels of IGF-I, IGF-II, IGFBP-1, and IGFBP-3. J Clin Invest 98:2612-2615

48. Barker DJ, Hales CN, Fall CH, Osmond C, Phipps K, Clark PM (1993) Type 2 (non-insulin-dependent) diabetes mellitus, hypertension and hyperlipidaemia (syndrome $\mathrm{X}$ ): relation to reduced fetal growth. Diabetologia 36:62-67

49. Phillips DI (1993) Twin studies in medical research: can they tell us whether diseases are genetically determined? Lancet 341:1008-1009

50. Christiansen L, Frederiksen H, Schousboe K et al (2003) Age- and sex-differences in the validity of questionnaire-based zygosity in twins. Twin Res 6:275-278 